\title{
Internationally Educated Nurses: Building Capacity for Clinical/Nurse Managers
}

Heather Hoxby, RN(EC), BScN, MHSc

Director of Nursing

St. Joseph's Healthcare Hamilton (SJHH)

Verla Fortier, RN, MHSc (Health Admin)

Senior Consultant Nursing Recruitment and Retention

Hamilton Health Sciences (HHS)

Nancy Brown, MAEd

Program Manager

Bridging for Internationally Educated Nurses (BIEN)

Gail Yardy, MSW

Executive Director

Centre for Internationally Educated Nurses (CARE)

Jennifer Blythe, $\mathrm{PhD}$

Associate Professor

McMaster University

Nursing Health Services Research Unit (NHSRU)

The purpose of this demonstration project was to provide clinical nurse managers with resources to increase their knowledge and confidence in hiring, managing and retaining internationally educated nurses (IENs). Two teaching hospitals, two organizations providing educational and other support programs for IENs, a community settlement organization and a nursing research unit collaborated in the project.

A questionnaire (response rate $37 \% ; N=33$ ) was administered to explore managers' needs for information on hiring and retaining IENs. Two focus groups were also held at each hospital, with a total of 17 managers. Based on these inputs, information resources were selected, evaluated and posted on the hospitals' Sharepoint websites, platforms used for information sharing and team processes. 
Approximately 20 managers attended a half-day workshop on hiring and retaining IENs. Participant satisfaction was assessed through an electronic post-workshop quiz and a post-intervention survey.

The needs assessment indicated that managers required additional knowledge and resources to improve recruitment and management of IENs. The half-day workshop was evaluated as moderately successful. Delays associated with implementing metrics on the Sharepoint website and low response rate to the post-implementation questionnaire limited the utility of the two evaluation procedures.

This demonstration project indicated that ongoing commitment is required to improve the integration of IENs into Ontario healthcare organizations. We need to expand our work on meeting the needs of clinical nurse managers to include educators, mentors and all nurses in the organization. Future directions will include further development and sustainability of IEN Sharepoint sites.

\section{Lessons Learned}

- Cultural diversity needs to be set as a priority by governing boards, CEOs and senior management to achieve system-wide change.

- Clinical educators, mentors and all nurses should be included in future interventions to better integrate IENs into the workplace.

- Formalization of collaborative relations among community organizations and academic and healthcare organizations is essential to facilitate knowledge exchange and innovative interventions.

Correspondence may be directed to: Heather Hoxby hhoxby@stjoes. ca. 